\title{
Percutaneous ultrasound guided drainage of abdominal abscesses
}

\author{
Misauno M. A ${ }^{1,}$, Sule A. $Z^{1}$, Ale A. F ${ }^{1}$, Isichei M. W' ${ }^{1}$ Ismaila B. $\mathbf{O}^{1}$, Ibilibor C. ${ }^{2}$ \\ ${ }^{1}$ Department of Surgery, Jos University Teaching Hospital, P.M.B 2076, Plateau State Nigeria \\ ${ }^{2}$ Department of Physiology, University of Jos, Jos Plateau State Nigeria
}

\section{Email address:}

micoyedim@yahoo.co.uk(Misauno M. A)

\section{To cite this article:}

Misauno M. A, Sule A. Z, Ale A. F, Isichei M. W, Ismaila B. O, Ibilibor C.. Percutaneous Ultrasound Guided Drainage of Abdominal Abscesses. International Journal of Medical Imagine. Vol. 1, No. 2, 2013, pp. 23-25. doi: 10.11648/j.ijmi.20130102.12

\begin{abstract}
Intraabdominal abscesses are common surgical pathologies that result from a myriad of causes and require a high index of suspicion to diagnose. Majority of the patient's present critically ill requiring surgical drainage. The traditional open surgical drainage is associated with a high morbidity and mortality. Percutaneous ultrasound guided drainage which entails either needle aspirations or image guided catheter placements for a thick abscess is a suitable alternative to open surgical drainage. This study was aimed at evaluating our experience with ultrasound guided percutaneous drainage of intraabdominal abscesses in a Teaching hospital in north central Nigeria. Methodology Consecutive patients diagnosed to have intraperitoneal abscesses in a general surgery unit at Jos University Teaching Hospital over a 24 month period were studied. Results Twenty four patients were involved in this study. There were 14 males and ten females giving a male to female ratio (M: $\mathrm{F}=1.4: 1)$. The mean age of the study population was $40+/-19.3$ with age range of $10-70 y e a r s$. Ten patients $(41.7 \%)$ had abscesses in the liver, $6(25 \%)$ in the pelvis and $5(20.8 \%)$ were subphrenic in location, 3(12.5\%) were psoas abscesses. Fifteen patients $(62.5 \%)$ had their abscesses drained by needle aspiration while the remaining $9(37.5 \%)$ were drained through placement of Foley's catheters. There was no mortality in this study. In conclusion, percutaneous ultrasound guided drainage of abdominal abscesses is a viable alternative to open surgical drainage.
\end{abstract}

Keywords: Abdominal Abscess, Drainage, Percutaneous, Ultrasound

\section{Introduction}

Intraabdominal abscesses are common life threatening surgical pathologies that could occur spontaneously or as a complication of abdominal pathologies and surgical procedures.(1-5) Common as they are however, a high index of suspicion is needed to clinch the diagnosis and cross sectional imaging techniques like ultrasound and CT Scans are very useful in this regard.(6,7) Most patients with intraabdominal abscesses are usually very ill and toxic, and of poor anaesthetic risk. $(8,9)$ Surgery in these patients is traditionally carried out via the open access (laparotomy) technique which is associated with a high morbidity from adhesions and residual abscesses and a high mortality.(10,11) Percutaneous ultrasound guided drainage of abdominal abscesses presents itself as a safer and less invasive method of draining these abscesses in these critically ill patients. The technique entails either needle aspirations or image guided catheter placements for thick abscesses.(12,13) The advantages of this method include reduced morbidity and mortality from anaesthesia and trauma of open surgery; it also ensures faster return to work and is comparatively cheaper (13-15). These advantages make percutaneous image guide drainage of abscesses a suitable procedure in resource scarce settings. This study was therefore aimed at evaluating our experience with ultrasound guided percutaneous drainage of intraabdominal abscesses in a Teaching hospital in north central Nigeria.

\section{Main Body}

\subsection{Patients and Methods}

This was a prospective study of consecutive patients diagnosed to have intraperitoneal abscesses in a general surgery unit at Jos University Teaching Hospital over a 24 month period (January 2009-December 2010).

Consecutive patients with intraperitoneal abscesses were assessed both clinically and radiologically and their 
suitability for drainage was determined before recruitment into the study. All patients with clinical suspicion of intraperitoneal abscess had abdomino-pelvic ultrasound scans done by the authours to confirm and localize the abscess and determine its suitability for percutaneous drainage. Exclusion criteria; Patients with abscesses that were multiple, multi-loculated, interloop, thick-walled abscesses (exceeding $1 \mathrm{~cm}$ ) and those with generalized peritonitis were excluded from this study. Data obtained included the age, sex, location of abscess, predisposition to abscess formation, method of drainage, volume of pus drained and complications. Data was analysed for means and standard deviations using Epi-info version 3.5.2

\subsection{Results}

A total of Twenty four patients were involved in this study. There were 14 males and ten females giving a male to female ratio ( $\mathrm{M}: \mathrm{F}=1.4: 1)$. The mean age of the study population was $40+/-19.3$ with age range of $10-70$ years. Ten patients $(41.7 \%)$ had abscesses in the liver, 6(25\%) in the pelvis and $5(20.8 \%)$ were sub-phrenic in location, $3(12.5 \%)$ were psoas abscesses. Nine patients $(37.5 \%)$ had no predisposition to abscess formation, 9 (37.5\%) had postoperative abscesses and $3(12.5 \%)$ were HIV positive, and another $3(12.5 \%)$ were from Tuberculosis.

In Fifteen patients (62.5\%), abscesses were drained by needle aspiration while the remaining 9 (37.5\%) were drained through placement of Foley's catheters (see fig.1).

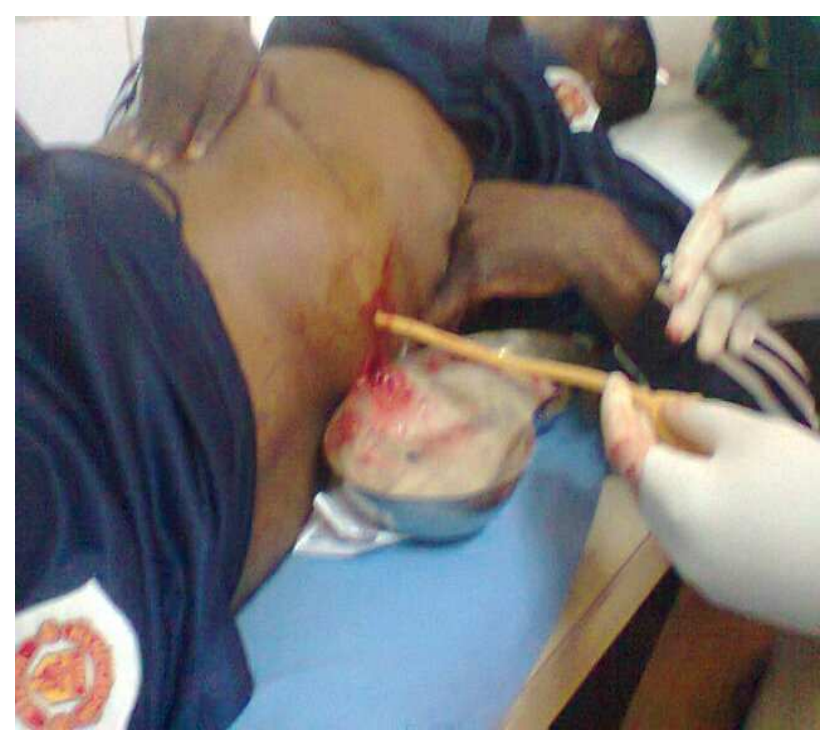

Fig. 1. percutaneous ultrasound guided drainage of a left psoas abscess

The average volume of pus drained was $817+/-650 \mathrm{ml}$

Sixteen patients $(66.7 \%)$ were on hospital admission while $8(33.3 \%)$ were done as day cases.

One patient $(4.2 \%)$ had generalized peritonitis complicating aspiration and required emergency exploratory laparotomy while the others were discharged home in good clinical condition.

There was no mortality in this study.

\subsection{Discussion}

This study shows that liver abscesses were the most common location for intraabdominal abscesses. This may be due to the fact that we are in a tropical low resource setting with the attendant poor food hygiene and relative water scarcity which predispose to amoebic liver abscesses. This agrees with the reported work of Bozkurt et al where liver abscesses were the most common accounting for $45.2 \%$ of the abscesses drained (16)

This study also revealed that abscesses complicating abdominal surgical operations (post-operative) were equally common. This is because most abdominal surgical operations in this research were performed for pathologies associated with sepsis like bowel perforations. This finding is in consonance with that of Gerzof et al who had post-operative abscesses accounting for $66.7 \%$ of their patients.(6) This study also reveals that with careful selection, abdominal abscesses in different locations can be safely drained with care not to injure adjacent viscera or blood vessels. That this procedure can be carried out on day care basis in patients that are not so ill after initial observation attests to its safety and simplicity in a carefully selected patient population.

\section{Conclusion}

Percutaneous ultrasound guided drainage of abdominal abscesses is a viable alternative to open surgical drainage.

\section{References}

[1] Kim NR, Chung DH, Lee WS, Cho HY. Intraabdominal abscess caused by actinomycosis in a patient with mesenteric fibromatosis of the small intestine: report of a case. Surg Today. 2012 Nov;42(11):1091-5.

[2] Shih YJ, Hsu KF, Yu JC, Chan DC, Hsieh CB. Synchronous hepatocellular carcinoma and sigmoid colon metastasis presenting as liver and intra-abdominal abscesses. Acta Gastroenterol Belg. 2012 Jun;75(2):278-9.

[3] Ong GY, Changchien CS, Lee CM, Wang JH, Tung HD, Chuah SK, et al. Liver abscess complicating transcatheter arterial embolization: a rare but serious complication. A retrospective study after 3878 procedures. Eur J Gastroenterol Hepatol. 2004 Aug;16(8):737-42.

[4] Montgomery RS, Wilson SE. Intraabdominal abscesses: image-guided diagnosis and therapy. Clin Infect Dis. 1996 Jul;23(1):28-36.

[5] Jung HG, Kim do H, Lee CH. [A case of subcapsular liver abscess secondary to perforating ulcer of gastric cancer]. Korean J Gastroenterol. 2010 Aug;56(2):109-13.

[6] Gerzof SG, Robbins AH, Birkett DH, Johnson WC, Pugatch RD, Vincent ME. Percutaneous catheter drainage of abdominal abscesses guided by ultrasound and computed tomography. AJR Am J Roentgenol. 1979 Jul;133(1):1-8.

[7] Turunc T, Demiroglu YZ, Colakoglu S. [Retrospective evaluation of 15 cases with psoas abscesses]. Mikrobiyol Bul. 2009 Jan;43(1):121-5. 
[8] Cerullo G, Marrelli D, Roviello F, Rampone B, Ferrari FS, Vigni F, et al. Treatment of the intraabdominal abscesses through percutaneous ultrasound-guided drainage in oncological patients: Clinical and microbiological data. Surg Endosc. 2008 May;22(5):1200-5.

[9] Bailey CM, Thompson-Fawcett MW, Kettlewell MG, Garrard C, Mortensen NJ. Laparostomy for severe intraabdominal infection complicating colorectal disease. Dis Colon Rectum. 2000 Jan;43(1):25-30.

[10] vanSonnenberg E, Ferrucci JT, Jr., Mueller PR, Wittenberg J, Simone JF, Malt RA. Percutaneous radiographically guided catheter drainage of abdominal abscesses. JAMA. 1982 Jan 8;247(2):190-2.

[11] Spencer J. What is needed from imaging? The surgeon's point of view. Scand J Gastroenterol Suppl. 1994;203:1-4.

[12] Stanley P, Atkinson JB, Reid BS, Gilsanz V. Percutaneous drainage of abdominal fluid collections in children. AJR Am J Roentgenol. 1984 Apr;142(4):813-6.
[13] Halasz NA, van Sonnenberg E. Drainage of intraabdominal abscesses. Tactics and choices. Am J Surg. 1983 Jul;146(1):112-5.

[14] Jahne J, Meyer HJ, Grote R, Milbradt H, Pichlmayr R. "Conservative" treatment of intra-abdominal complications after total gastrectomy with interventional radiological techniques. Surg Endosc. 1989;3(1):16-20.

[15] Braun B, Dormeyer HH. Ultrasonically guided fine needle aspiration biopsy of hepatic and pancreatic space-occupying lesions and percutaneous abscess drainage. Klin Wochenschr. 1981 Jun 15;59(12):707-12.

[16] Bozkurt T, Butsch B, Langer M, Lux G. [Percutaneous sonographically guided fine-needle puncture and drainage of pyogenic abscesses]. Dtsch Med Wochenschr. 1991 Dec 20;116(51-52):1943-7. 